\title{
Teaching Inventory Management Simulation Using E-Learning Software: Blackboard, Elluminate Live!, and Jing
}

\author{
Joel Oberstone, Professor \\ University of San Francisco/School of Business and Management, San Francisco, CA, USA
}

\begin{abstract}
Introducing the nuances of inventory management systems to undergraduate business students can be a daunting task. Beyond the traditional focus of the selection of order quantity and reorder point lie more murky considerations such as the impact that stockout cost and supplier selection have on these key parameters, including profit. The purpose of this paper is to illustrate how students can cultivate insights of business simulation settings through easy-to-run, downloadable Excel spreadsheet templates from within their Blackboard-driven course website beyond merely grinding out "answers.” This paper shows not only how the simulation templates are employed but also how students can use them to self-correct problems they might encounter during the learning process, how to examine more subtle issues, and how the instructor can use online software to guide students in real time, regardless of the distance that may separate them. Further, while these interactions are taking place, a video software file can be made to memorialize the online learning and can be easily uploaded to the student for their later use should they wish to practice the process. A hypothetical case example of AT\&T's management of the Apple iPhone inventory is used to illustrate the process.
\end{abstract}

Index Terms-Spreadsheet simulation, inventory management, E-Learning.

\section{INTRODUCTION}

In many real-world settings, the depletion pattern of inventories and the lead time necessary to replenish the falling stock do not follow convenient, algebraicallystructured models. Instead, these variables often follow unique, random distributions that can only be defined by empirical data collection and their uncertain behavior, illustrated through simulation.

Although there are numerous simulation software products available, the proficiency needed to effectively employ them can involve a relatively steep learning curve $[1,2]$. This is particularly true when it comes to a single semester or quarter QBA course offering since it is only one of the several techniques in the total array of skills to be covered $[3,4,5,6,7,8,9]$. Even though simpler simulation tools such as Excel spreadsheet add-ins Crystal Ball [10] and @RISK [11] are available, neither is crossplatform and both require an additional expense to either the student or university or both. ${ }^{1}$ Additionally, both

${ }^{1}$ Some quantitative textbooks offer a time-limited version of these software. Of course, if the text is not the preferred one, few teachers will use this software acquisition option.
Crystal Ball and@RISK require moderate skills to create the additional features of a discounted inventory system characterized by uncertain demand and stock lead time $[12,13,14,15,16]$.

\section{Phase I-EXcel SpREAdSheEt InVENTORY Management Simulation TEMPLATE: A Quick- CHANGE DESIGN}

As an alternative to simulation software, a baseline, ready-to-run Excel inventory management template is stored at my Blackboard website that can downloaded by enrolled students at any time and as often as needed. A version of this spreadsheet is shown in Figure 1.

There are numerous advantages to using self-contained spreadsheets. One of the most important features of this proposed spreadsheet is its ability to be quickly converted into the "next" inventory system to be simulated, e.g., the template that is, say, initially used to analyze the operation of a Pirelli Tire dealership inventory system can be easily "flipped" into a Best Buy analysis of its Canon digital camera inventory in a matter of a few minutes. Additionally, the spreadsheet has a multilevel product discount table to address the possible advantages of larger purchase quantities. A detailed description of the spreadsheet operation is given in Appendix A.

\section{A. Template Input Parameters}

The baseline spreadsheet template uses the following data to generate the best inventory management parameters, $\mathrm{Q}^{*}$ and $\mathrm{R}^{*}$ : $^{1}$

- Product holding, ordering, and stockout costs (E9:G9)

- Four-tier supplier discount table (J9:K12) the wholesale product costs (L9:L12), and the product retail price, MSRP (M9)

- A specific combination of order quantity, Q (G11) and reorder point, $\mathrm{R}$ (G12)

- Data sets for the samples of random variables product demand, D, and supplier lead time, L are organized into probability distributions that are used to randomly generate values of $\mathrm{D}$ and $\mathrm{L}$ during the 30-day simulation. ${ }^{2}$

\footnotetext{
${ }^{1}$ The parentheses statements, e.g., (E9:G9), indicate Excel cell array addresses in Figure 1.

${ }^{2}$ The probability distributions are used to construct a VLOOKUP table that imitates the behavior of the empirical data collected for demand and lead time.
} 


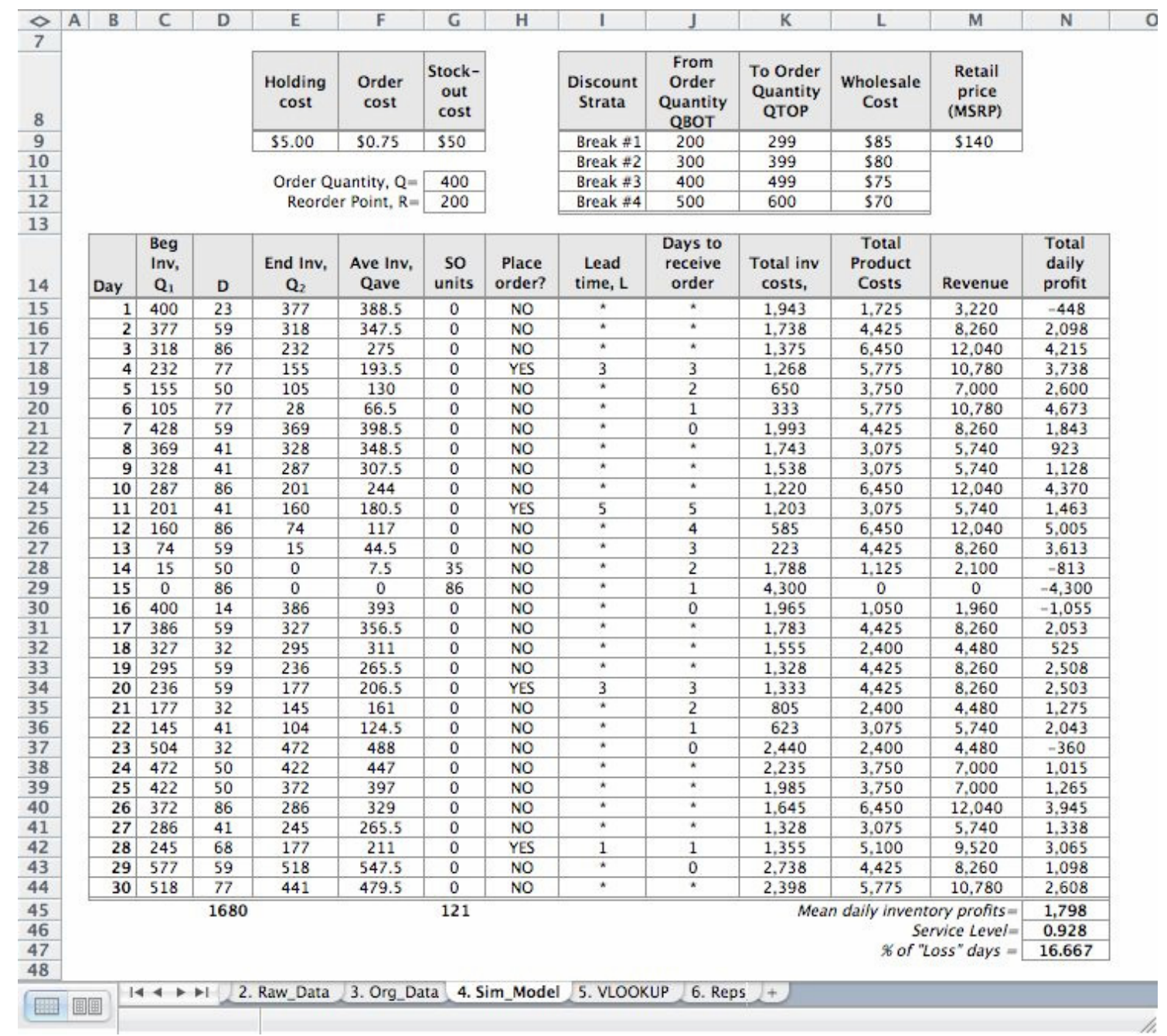

Figure 1. Excel 30-Day Baseline Inventory Simulation Template $(\mathrm{Q}=400, \mathrm{R}=200)$

\section{B. Template Output/Performance Parameters}

The simulation is initiated by using the calculate command: F9 for Windows or $\mathscr{H}=$ for Macintosh. The 30 - day business cycle is then automatically replicated 200 times for 25 specific Q-R combinations. ${ }^{3}$

1. The five (5) Q-values selected are "edge" values of the discount table: the lower limit values for the four price breaks given in cells J9:J12 plus the largest value of the fourth break, K12.

2. In turn, each Q-value is paired with five (5) reorder point values, $R$, equal to $10,30,50,70$, and 90 percent of the $Q$ value, e.g., the template values of $\mathrm{Q}=200,300,400,500$, and 600 are each examined with corresponding $\mathrm{R}$ values of $.10 \mathrm{Q}, .30 \mathrm{Q}$, $.50 \mathrm{Q}, .70 \mathrm{Q}$, and $.90 \mathrm{Q}{ }^{4}$

These baseline parameters are quickly "changed-out" or "flipped" with the result that the baseline inventory system is painlessly transformed into a completely fresh product simulation. It usually takes students less than

\footnotetext{
${ }^{3}$ Later, the influence of replications on the level of confidence and the tolerable error of the simulation are reviewed.

${ }^{4}$ As an example, an order quantity of $\mathrm{Q}=200$ units will be automatically replicated with $\mathrm{R}$ combinations of $20,60,100$, 140 , and 180 units.
}

two 90-minute class sessions to effectively manipulate the baseline model template. In two more sessions, they have gained a level of comfort with changing the baseline spreadsheet values to accommodate a different product and to generate new inventory system parameters. They can see the baseline template mean daily profit of about $\$ 2,200$ per day for a Q-R combination of 500 and 175 units (Figure 2) transformed into the AT\&T iPhone spreadsheet that produces a daily profit of approximately $\$ 22,700$ for a Q-R combination of 3,000 and 1,500 units, respectively (Figure 3). ${ }^{5}$ The 200 "flip" replications of all 25 Q-R combinations are completed in less than 2 minutes.

By reducing the need for number grinding, using overly simplified algebraic inventory models, or employing dedicated simulation software of any kind, the student is now able to shift attention to more nontraditional inventory management considerations discussed next.

\footnotetext{
${ }^{5}$ The selection of the three output performance factors of service level, mean daily profit, and percent of "loss" days is arbitrary. The spreadsheet can be easily modified to look at other criteria such as number of monthly orders placed, percent of time profit exceeds or falls below a specified amount, etc.
} 


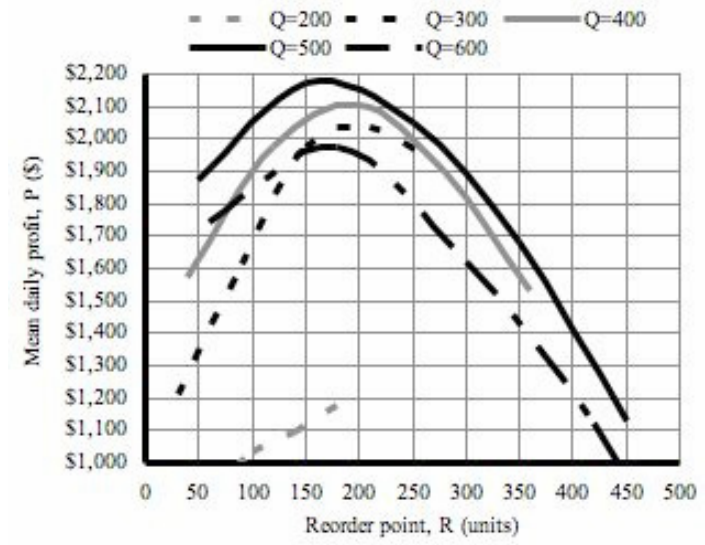

Figure 2. Baseline Excel Simulation Template Mean Daily Profit (stockout cost $=\$ 150 /$ unit)

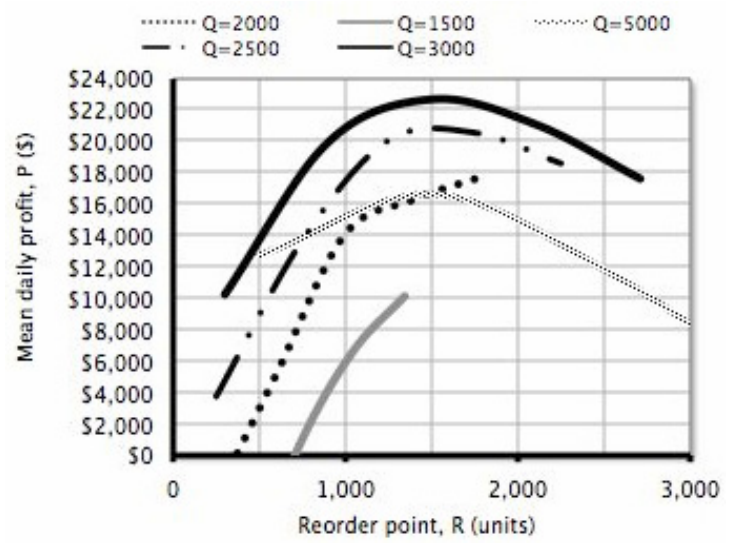

Figure 3. AT\&T-iPhone Inventory Simulation for Mean Daily Profit (stockout cost $=\$ 400 /$ unit)

\section{Phase II-EXPLORING BEYOND THE BASICS OF INVENTORY MANAGEMENT: CONNECTING REAL WORLD IMPACT}

The employment of our simple, Blackboard-posted, Excel spreadsheet template provides students with a quick and easy way to manipulate numerous inventory system elements and to quickly see how these changes alter system performance. The traditional, fundamental issues such as, "How many units should we order and how far do we let our supply fall before placing a new order?" are easily determined and allow more sophisticated topics to be covered. Here are a few examples of these issues and student responses:

Q1. "Lost sales resulting from inventory shortage is a significant concern of inventory management [17]. What if management is unable to agree on assigning a value to stockout cost? Help them determine what influence, if any, this highly subjective parameter has in determining the inventory system parameters, i.e., order quantity, $\mathrm{Q}^{*}$ and reorder point, R.* Also, is there a significant impact on the mean daily profit, P?"

Response: As stockout cost increases from $\$ 0$ to $\$ 1,000$, the average daily inventory profit drops from about $\$ 27,300$ to $\$ 20,200$, respectively (Figure 4). This makes sense because higher shortage penalties will never help profits. Over this same range of stockout cost, the best order quantity remains constant at 3,000 units while reorder point increases from 900 to 2,100 units (Figure 5). This makes sense also because higher reorder points will generally make it less likely to experience stockouts. $^{6}$ This impact becomes increasingly pronounced as stockout cost increases.

Q2. "Can you suggest why factions of management might disagree on the "pricing" of stockout cost? What are a few scenarios that could support a high or low stockout cost pricings?"

Response: If AT\&T management views the iPhone as a disruptive technology - a product that is distinctly innovative and currently dominates the marketplace - then low stockout costs are defensible. Why? Because if the buyer wants the product, AT\&T is the only "show in town", i.e., only they sell it. On the other hand, if AT\&T feels that even though the iPhone is a strong product, the market place of other PDA-type cell phones is so competitive that a buyer would likely purchase another product — such as a Blackberry from Verizon - the loss would include not only the price of the cell phone sale but would also consist of the revenues lost from the typical two-year user contract and word-of-mouth ill-will. This loss could amount to well over a $\$ 1,000$ stockout cost. For sake of argument, let's say that management believes the competition places the stockout cost somewhere closer to the $\$ 400$ price of the product. If we use this assumption, Figure 5 supports the selection of a reorder point of approximately 1,650 units to compliment the 3,000-unit order quantity.

Q3. "Suppose that AT\&T is concerned about Apple's history of product delivery problems [18]. AT\&T then asks Apple if a faster delivery alternative is available. In response, Apple offers AT\&T a faster lead time but increases the order cost for each iPhone unit from $\$ 4.00$ to $\$ 10.00$. Is the higher premium justified?"

Response: In order to see if the more costly, shorter lead-time is justified, we need to rerun the simulation using the shorter lead-time distribution and, additionally, increase the order cost to $\$ 10$. In fact, if we don't want to assume that management will agree on a specific stockout cost, then the entire range of stockout cost values between $\$ 0$ to $\$ 1,000$ per shortage unit will need to be reassessed as well. These findings reveal that unless a very low stockout cost of no more than $\$ 50-60$ is agreed upon, the faster, more expensive delivery option will deliver consistently higher daily profits (Figure 6). 


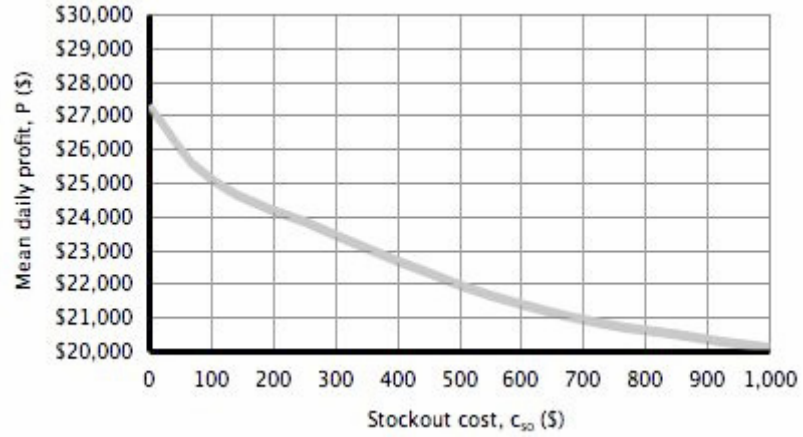

Figure 4. AT\&T iPhone Impact of Stockout Cost on Mean Daily Profit (order cost $=\$ 4 /$ unit)

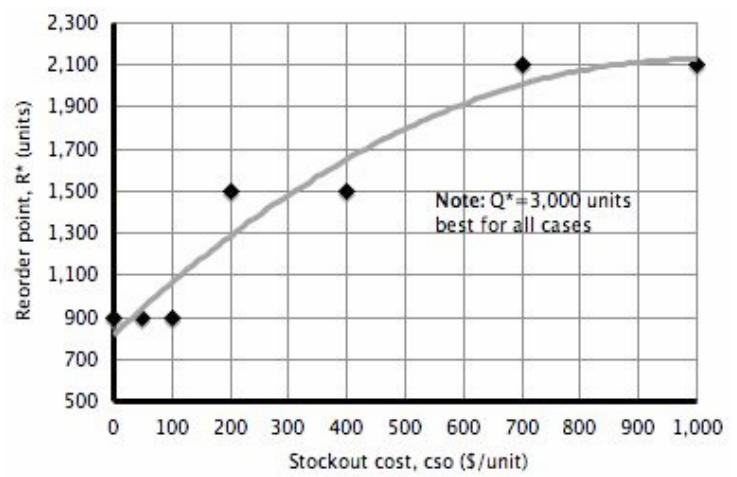

Figure 5. Influence of Stockout Cost on Reorder Point, for AT\&T iPhone Inventory

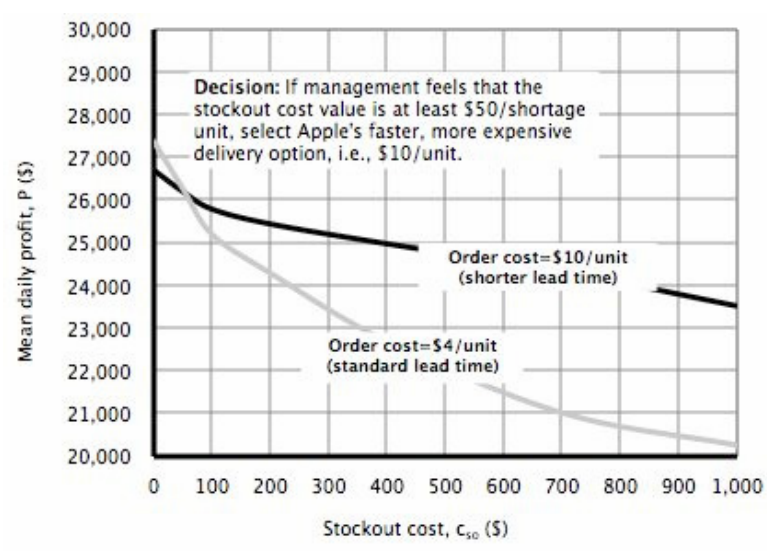

Figure 6. Comparing Standard Versus Premium Apple Delivery Options for AT\&T iPhone

\section{Phase III-Memorializing The Learning WITH ELLUMINATE LIVE! AND JING}

\section{A. Synchronous E-Learning}

Traditional office hours are used to supplement the class meetings. Additionally, internet-hosted, or synchronous learning tutorials that includes live, online support via a virtual meeting room, are also arranged for those students not able to attend the regular office sessions. Elluminate Live! is a web-hosted environment that helps the teacher to create a real-time, interactive, virtual office space with both audio and visual conferencing, a shared whiteboard to conduct "work," and the ability to share applications [19]. Regardless of where students are geographically located, type of computer operating system used, or internet connection, the instructor can interact with one, two, or dozens of students in the Elluminate Live! virtual office called a vRoom. A typical session is set up like this:

1. After the instructor (moderator) signs into the Elluminate Live! website, a java script is downloaded onto his/her desktop. Opening the script starts the Elluminate Live! session that creates a virtual meeting room, complete with audio and visual access controlled by the moderator. This step takes about 90 seconds.

2. The moderator then posts the Elluminate Live! link at the Blackboard course website and either group emails all course-enrolled students or selectively invites a particular group of students if it is a special session. Participating students will simply click the link, a java script immediately downloads onto his/her desktop, and the session begins.

3. Each student has an inexpensive microphone and a headset to contribute and listen to other members in the session. Elluminate Live! also walks the student through an audio check to insure that microphone and headset settings are acceptable.

Visual access to a "white board" or the host's desktop is the key to the session: it becomes the "live" demonstration of any features that students may have been experiencing problems. The moderator chooses which tools to use to visually support the subject of the conversation. This could include a white board presentation using drawing or graphing tools, a PowerPoint presentation, a Wall Street Journal article downloaded from the WSJ website to review together, or an Excel spreadsheet demonstration on building and formatting scatter diagrams The students sees, in real time, how the teacher manipulates a particular task and can ask questions regarding any unclear steps (Fig. 7). ${ }^{8}$

\section{B. Asynchronous E-Learning}

In order to further accommodate students who may not be able to attend a vRoom session, or even for those that would like to be able to review the tutorial content "anytime, anywhere," step-by-step, video clips of the more challenging operations are made and saved in a file that is stored at the Blackboard course website, e.g., charting skills, developing the random variable probability distributions, recording the replications, defining the confidence interval of the simulation, etc. The asynchronous software product used to record the video is briefly discussed next.

Jing is an audio and video screen capture tool that can be used to transparently record either the entire tutorial session or portions of the session [20]. The recording is saved so that it can then be shared with the student by either emailing the URL of the saved recording or posting it to the Blackboard website (or both). A screenshot of one these videos - in this case, the live Excel 30-day simulation template-is shown in Figure 8.

\footnotetext{
8 Any participant may interact after electronically indicating that they are "raising their hand" in the session-a necessary courtesy so all questions and answers can be heard and understood without being trampled over.
} 
The process is similar to using TIVo to record television programs for viewing at a later date. The student now has unlimited access to the "tutorial" and can practice the skills as often as desired. A particularly valuable feature of this process is that even students who are not highly interactive, who prefer to sit back during these sessions, can watch and reexamine specific tutorials created including those that they did not attend in any setting they wish. All of these tutorials are saved in a tutorial library and are downloadable throughout the course (Figure 9).

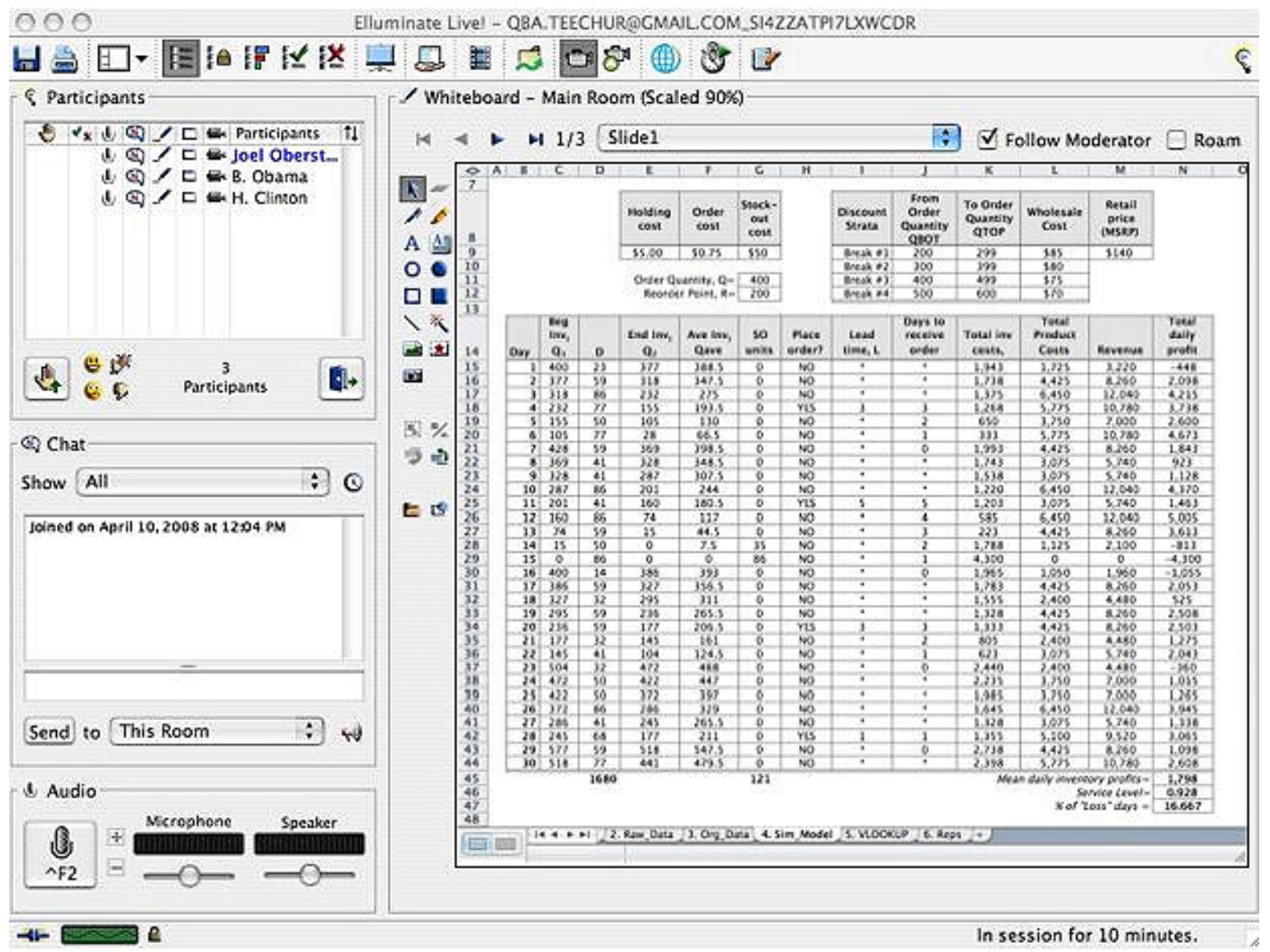

Figure 7. Elluinate vRoom White Board with Excel Simulation Template on Host Desktop

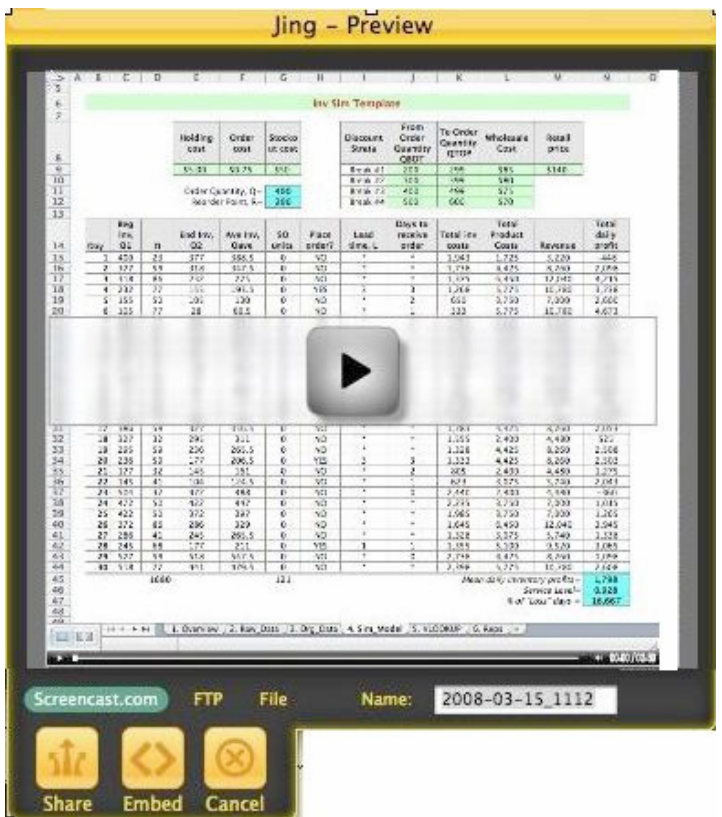

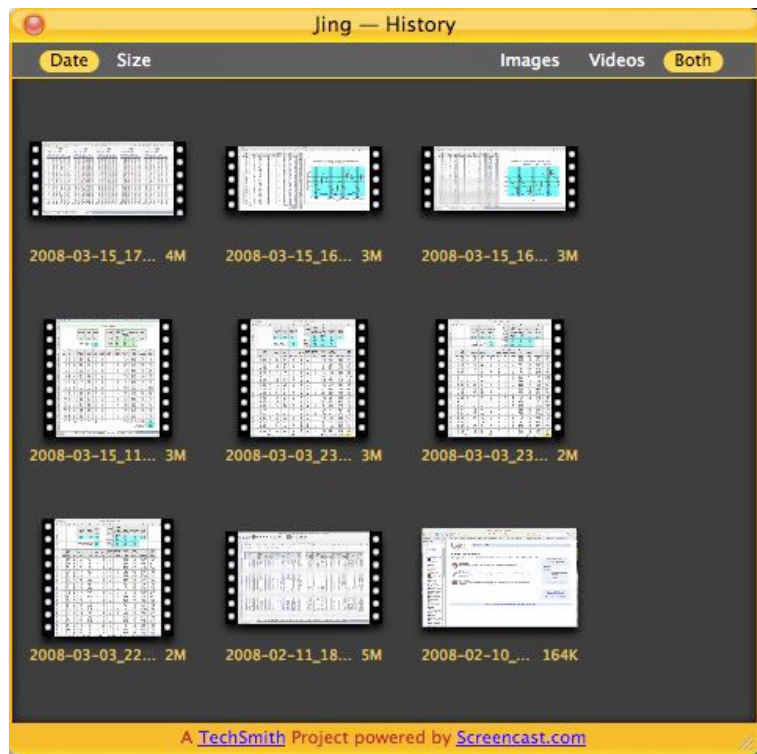

Figure 9. Jing Inventory Simulation Video Library

Figure 8. Jing Inventory Tutorial of 30-Day Inventory Operation 


\section{SUMMARY}

The standard collection of methodologies offered in an undergraduate quantitative business analysis course makes the time open to cover any single topic tightly compressed. Arguably, inventory simulation is one of the more challenging skills and begs the need to find creative ways to effectively teach this subject in the very limited time available. In order to accomplish this task, e-learning software products Blackboard, Elluminate Live! and Jing are woven into the course fabric to create extended, interactive online classroom learning opportunities called vRooms. In turn, students have the choice whether to be either an interactive member of the vRoom session or to be a "viewer." Regardless of whether they are active participants, the sessions are recorded in short videos that illustrate the computer procedures used, including every mouse click, screen, pull-down menus - everything! The videos are saved, stored at the courses Blackboard website and can be downloaded, reviewed, and practiced by the student at any time. Together, the collaboration of teaching method and software are integrated to make the learning process less intimidating for the student and, of no minor importance, fun for the teacher. Possibly of even greater importance, the process diffuses the more laborious traditional computational component of the topic and instead allows for greater exploration of more sophisticated issues then is typically covered during more common exposures to inventory management.

Finally, even though this paper focuses on undergraduate university students, the e-learning process described is equally applicable to a professional, workplace setting. At the end of the day, there little difference between a student who needs to demonstrate an understanding of course materials and a corporate employee who is expected to apply new skills gained from an in-house training workshop to his/her occupation. Far more important than any difference between audiences are the e-learning methods used in both the delivery and continued accessibility of the study materials.

\section{LIST OF SYMBOLS}

Q Order quantity of product (units)

$\mathrm{R} \quad$ Reorder point (units)

Q* Best order quantity (units)

$\mathrm{R}^{*} \quad$ Best reorder point (units)

$\mathrm{Q}_{1} \quad$ Beginning inventory (units)

$\mathrm{Q}_{2} \quad$ Ending inventory (units)

$\mathrm{Q}_{\text {ave }} \quad$ Average inventory (units)

SO Number of stockout/shortage units

D Daily demand (units)

L Order lead time (days)

$\mathrm{c}_{\mathrm{h}} \quad$ Per unit holding cost (\$/unit/day)

$\mathrm{C}_{\mathrm{h}} \quad$ Total holding cost (\$)

$\mathrm{c}_{\mathrm{o}} \quad$ Per unit order cost (\$/unit/order)

$\mathrm{C}_{\mathrm{o}} \quad$ Total order cost (\$)

$\mathrm{c}_{\mathrm{so}} \quad$ Per unit stockout cost (\$/unit)

$\mathrm{C}_{\mathrm{so}} \quad$ Total stockout cost (\$)

$\mathrm{C}_{\mathrm{t}} \quad$ Total inventory costs (\$)

$\mathrm{c}_{\mathrm{w}} \quad$ Wholesale product cost (\$/unit)
$\mathrm{C}_{\mathrm{w}} \quad$ Total product cost (\$)

MSRP Manufacturer suggested retail price (\$/unit)

$\mathrm{R}_{\$} \quad$ Daily revenue (\$)

P Total daily profit (\$)

\section{APPENDIX A. EXPLANATION OF EXCEL INVENTORY MANAGEMENT TEMPLATE EVENTS ${ }^{9}$}

1. The beginning inventory, $\mathrm{Q}_{1}$, is reduced by the demand for that day, D, if there is sufficient stock, ending the day at $\mathrm{Q}_{2}$. If there is insufficient stock to cover the daily demand, a shortage of SO units will be experienced of $\mathrm{SO}=\mathrm{D}-\mathrm{Q}_{1}$. For day $1, \mathrm{Q}_{1}=$ $\mathrm{Q}=400$ units, $\mathrm{Q}_{2}=\mathrm{Q}_{1}-\mathrm{D}=400-23=377$ units. (The reorder point used for this simulation is $\mathrm{R}=200$ units.)

2. The average inventory level, $\mathrm{Q}_{\mathrm{ave}}=\left(\mathrm{Q}_{1}+\mathrm{Q}_{2}\right) / 2=$ $(400+377) / 2=388.5$ units, is used to determine the holding cost component for that day, i.e., $\mathrm{C}_{\mathrm{h}}=\mathrm{c}_{\mathrm{h}} \mathrm{X}$ $\mathrm{Q}_{\mathrm{ave}}=(5)(388.5)=\$ 1,942.50$ or $\$ 1,943$; if there is a shortage for the day, there would also be a stockout cost calculated, $\mathrm{C}_{\mathrm{so}}=\mathrm{c}_{\mathrm{so}} \times \mathrm{SO}=50 \times \mathrm{SO}$, e.g., the first shortage of 35 units occurs during day 14, resulting in $\mathrm{C}_{\mathrm{so}}=\mathrm{c}_{\mathrm{so}} \times \mathrm{SO}=(50)(35)=\$ 1,750$. The additional holding costs occurring during day 14 are $\mathrm{Q}_{\text {ave }}$ × $5=(15+0) / 2$ × $5=\$ 37.50$. No product was ordered, so the total inventory costs for day 14 is $\$ 1,750+\$ 37.50=\$ 1,787.50$ or $\$ 1,788$.

3. A new order of $Q$ units will be placed if the ending inventory at the end of the day does not exceed the reorder point, $\mathrm{R}$, i.e., if $\mathrm{Q}_{2} \leq \mathrm{R}$, an ordering cost of $\mathrm{C}_{\mathrm{o}}=\mathrm{c}_{\mathrm{o}} \times \mathrm{Q}$. The first reorder launched occurs at the end of day 4 when the stock level drops below 200 units for the first time. The order cost component charged for this day is $C_{o}=(.75)(400)=\$ 300$. Since the holding cost for this day is $(5)(193.5)=$ $\$ 967.50$, the total inventory costs for day 4 is $\$ 1,267.50$.

4. If/when a new order is launched, the lead time, L, will be randomly generated and the days to receive the new order will count down over L days. On four (4) occasions during this 30-day period-days 4, 11, 20 and 28-the inventory level dips below 200 units and new orders are placed. These are the only days that will have an order cost component (and the only times during which stockout costs can accrue).

5. The total inventory costs are calculated for each day, i.e., $\mathrm{C}_{\mathrm{h}}+\mathrm{C}_{\mathrm{so}}+\mathrm{C}_{\mathrm{o}}=\mathrm{Q}_{\mathrm{ave}} \mathrm{x} \mathrm{c}_{\mathrm{h}}+\mathrm{c}_{\mathrm{sob}} \mathrm{x} \mathrm{SO}+\mathrm{Q} \mathrm{x}$ $\mathrm{c}_{\mathrm{o}}$.

6. Total wholesale product costs, $\mathrm{C}_{\mathrm{w}}$, are calculated using the demand satisfied during the day, i.e., $\mathrm{c}_{\mathrm{w}} \mathrm{x}$ $\left\{\mathrm{D}, \mathrm{Q}_{1}\right\}_{\min }$, e.g., for day 1, 23 units are sold and $\mathrm{C}_{\mathrm{w}}=\mathrm{c}_{\mathrm{w}} \times\left\{\mathrm{D}, \mathrm{Q}_{1}\right\}_{\text {min }}=(75)(23)=\$ 1,725$, where $\mathrm{c}_{\mathrm{w}}$ $=\$ 75$ per unit based on the third price break tier.

7. Daily revenue, $R_{\$}$, is calculated for total units sold based on retail sales price, MSRP, i.e., MSRP $\mathrm{x}$ $\left\{\mathrm{D}, \mathrm{Q}_{1}\right\}_{\text {min }}$, e.g., for day 1 , the same 23 units sold will generate revenues of $R_{\$}=(23)(140)=\$ 3,220$.

\footnotetext{
${ }^{9}$ Refer to 30-day Excel spreadsheet in Figure 1.
} 
8. Total daily profit $\mathrm{P}=\mathrm{R}_{\$}-\left(\mathrm{C}_{\mathrm{h}}+\mathrm{C}_{\mathrm{so}}+\mathrm{C}_{\mathrm{o}}+\mathrm{C}_{\mathrm{w}}\right)$, e.g., for day $1, \mathrm{P}=3,220-(1,943+0+0+1,725)$

$$
=-\$ 448 \text {. }
$$

\section{REFERENCES}

[1] J. J. Swain, 2007, "New Frontiers in Simulation: Biennial survey of discrete-event simulation software tools," OR/MS Today, Vol. 34, No. 5, pp. 32-35.

[2] J. J. Swaim, 2007, "Simulation Software Survey," OR/MS Today, Vol. 34, No. 5, pp. 36-43.

[3] C. Ragsdale (2001), "Teaching Management Science With Spreadsheets: From Decision Models to Decision Support," INFORMS Transactions on Education 1:2 (68-74).

[4] G. E. Monahan, Management Decision Making: Spreadsheet Modeling, Analysis, and Applications, Cambridge University Press, Copyright 2000.

[5] D. Bertsimas and R. Freund, Data Models and Decisions: The Fundamentals of Management Science, South-Western College Publishing, 2000.

[6] W. L. Winston (1996), "The Teacher's Forum: Management Science with Spreadsheets for MBAs at Indiana University," Interfaces, Vol. 26, No. 2, pp. 105-111.

[7] S. C. Albright and W. L. Winston, Spreadsheet Modeling and Applications: Essentials of Management Science, Brooks/Cole, 2005.

[8] R. Scheubrein, "Supporting Self-Studying of Students with a Spreadsheet-Based Tutoring Software," INFORMS 2005 Annual Meeting, San Francisco, MA03.2.

[9] J. Lawrence, "A distance learning approach to teaching management science and statistics," International Transactions in Operational Research, Volume 10, Issue 2, Page 127-139, Mar 2003.

[10] Crystal Ball ${ }^{\circledR}$, Oracle Crystal Ball Global business Unit, Denver, CO 80237, http://decisioneering.com/
[11]@RISK, Palisades Corporation, Ithica, NY 14850, http://www.palisade.com/

[12] J. R. Evans (2000), "Spreadsheets as a Tool for Teaching Simulation," INFORMS Transactions on Education 1:1 (27-37).

[13] L. Goldman, "Spreadsheet Simulation and Modeling Using Crystal Ball Professional," INFORMS 2004 Annual Meeting Denver, CO, ID : SB47.1.

[14] W.L. Winston (2000), Simulation Modeling Using @RISK: Updated for Version 4, Brooks/Cole, Belmont, CA.

[15] J. Eckstein and S.T. Riedmueller (2002), "Yet Another Add-in for Teaching Elementary Monte Carlo Simulation in Excel" INFORMS Transactions on Education, Vol. 2, No. 2.

[16] P. J. Regan (2006), "Professional Decision Modeling: Practitioner as Professor," Interfaces, Vol. 36, No. 2, pp. 142-149.

[17] D. B. Bandy, "In-Class Simulation of Pooling Safety Stock," Decision Sciences Journal of Innovative Education, Volume 3, Issue 2, Page 375-380, Jul 2005.

[18] C. Hameerschmidt, "Sharp is Bottleneck for iPhone," EE Times Europe, June 26, 2007.

[19] Elluminate, $6301 \mathrm{NW} 5^{\text {th }}$ Way, Suite 3600 , Ft. Lauderdale, FL 33309-6197, http://www.elluminate.com

[20] TechSmith Corporation, Jing Project, 2405 Woodlake Drive, Okemos, MI 48864-5910, http://www.jingproject.com/

\section{AUTHOR}

Joel Oberstone is with theUniversity of San Francisco/School of Business and Management, San Francisco, CA 94117.

Manuscript received 14 April 2008. Published as submitted by the author. 